\title{
Gênese de Noções Matemáticas Elementares: concepções epistemológicas subjacentes às respostas de docentes de Matemática de três países sulamericanos
}

\author{
Genesis of Elementary Mathematical Notions: epistemological conceptions \\ underlying the answers of Mathematics teachers from three South
}

\author{
American countries
}

Fernando Becker

ORCID iD 0000-0003-4215-9805

\begin{abstract}
Resumo
O texto apresenta a segunda parte da análise da pesquisa Epistemologia do Professor de Matemática; fase internacional, cujos dados foram coletados no Peru, Chile e Uruguai junto a docentes de Matemática. O objetivo é identificar as concepções epistemológicas docentes que fundamentam o ensino de Matemática e conferir se tais concepções são equivalentes às encontradas no Brasil: empiristas, amparadas frequentemente por aprioristas; e, raramente, construtivistas. O objetivo geral da pesquisa será buscado, neste texto, pelo objetivo específico: saber em que etapa da infância humana os docentes situam o surgimento das noções matemáticas necessárias para que a criança efetue operações matemáticas básicas e a que eles atribuem sua gênese. Analisam-se para isso as respostas às questões 4 a 8 da pesquisa, feitas a docentes de todos os níveis de ensino, mediante entrevistas. Assemelham-se as respostas dos docentes aos resultados brasileiros quanto à predominância de concepções empiristas, fundadas por concepções aprioristas. Concepções construtivistas aparecem na fala de apenas um professor dos dezessete entrevistados. Acreditam os docentes no surgimento precoce de noções matemáticas básicas, atribuindo-as à pressão do meio, mediante estimulação e repetição, configurando empirismo, e, frequentemente, à herança genética ou à maturação, configurando apriorismo, inclusive inatista. Confundem construções lógicas, realizadas pela criança, do nascimento aos $7 / 8$ anos, com noções matemáticas básicas. Atribuem seu surgimento à estimulação (fundamentada pela maturação), com desvalorização da ação do sujeito, de seu processo de desenvolvimento cognitivo; atribuem à percepção o que é mérito da ação e das coordenações das ações do sujeito no interior do processo de abstração reflexionante. Consideram, por isso, hegemônico o processo de ensino frente ao de aprendizagem. A referência teórica básica é a Epistemologia Genética piagetiana.
\end{abstract}

Palavras-chave: Construção do Conhecimento Matemático. Epistemologia do Professor de Matemática. Gênese de noções matemáticas elementares.

\begin{abstract}
This work presents the second part of Epistemology of the Mathematics Professor; the international phase research analysis, which data were collected in Peru, Chile, and Uruguay from mathematics teachers. The objective is to identify in teachers the epistemological conceptions that underlie the teaching of Mathematics and investigate if these conceptions are equivalent to those found in Brazil: empiricists (substantiated sometimes by apriorists), and, rarely, constructivists. The general research objective will be pursued, in this text, by the specific objective: to
\end{abstract}

\footnotetext{
* Doutor em Psicologia Escolar e do Desenvolvimento Humano pela Universidade de São Paulo (USP). Professor Titular da Universidade Federal do Rio Grande do Sul (UFRGS), Porto Alegre, Rio Grande do Sul, Brasil. E-mail: fbeckerufrgs@gmail.com.
} 
know in which stage of human childhood teachers place the emergence of the necessary mathematical notions for the child to perform basic mathematical operations; and to what they attribute its genesis. For this, we analyze the answers to research questions 4 to 8, asked to teachers of all levels of education, through interviews. The responses given are similar to those of Brazilian teachers in relation to the predominance of empiricist conceptions founded by apriorist ones. Constructivist conceptions are found in only one of the seventeen research interviews. Teachers believe in the early appearance of basic mathematical notions, attributing them to environment pressure, through stimulation and repetition, configuring an empiricist conception; and, frequently, to genetic inheritance or maturation, configuring an apriorism, even innate. They confuse logical constructions, performed by the child from birth to about 7 or 8 years of age, with basic mathematical notions. They attribute its appearance to stimulation (based on maturation), with a devaluation of the subject's action and of their cognitive development process; they attribute to perception what is the merit of action and the coordination of the subject's actions within the process of reflecting abstraction. Teachers consider, therefore, the teaching process to be hegemonic over the learning process. The basic theoretical reference is Piaget's Genetic Epistemology.

Keywords: Construction of Mathematical Knowledge. Epistemology of the Mathematics Teacher. Genesis of elementary mathematical notions.

\section{Introdução}

Este texto apresenta a segunda parte da análise da pesquisa "Epistemologia Subjacente ao Trabalho Docente; fase internacional" com dados coletados, mediante entrevistas, no Chile, Uruguai e Peru, junto a 17 docentes de Matemática de todos os níveis de ensino. A primeira foi publicada pelo BOLEMA - Boletim de Educação Matemática (BECKER, 2019). Relembrando brevemente os dados: trata-se de pesquisa que dá continuidade a duas pesquisas anteriores já publicadas em livros: Epistemologia do professor; o cotidiano da escola (BECKER, 2018) e Epistemologia do professor de matemática (BECKER, 2012b). A intenção desta pesquisa é saber se os problemas epistemológicos que comprometem o ensino brasileiro de Matemática, como indicam essas análises, aparecem também fora do Brasil.

Dezessete professores de Matemática, com idade de 25 a 68 anos - de Ensino Fundamental (três), Ensino Médio (cinco) e universitário (dez), sendo que um leciona no Fundamental e Médio - foram entrevistados, em 2014, com 24 questões. A maioria deles ensina em instituições públicas, inclusive de periferia; outros em instituições privadas, inclusive de elite. Lecionam Cálculo, Equações Diferenciais, Geometria, Aritmética, Álgebra, Análise, Tabuada. Explicada a intenção da pesquisa e garantido o anonimato, as entrevistas foram realizadas com gravação em áudio e, posteriormente, desgravadas e transcritas para o português.

A pesquisa inspira-se, para as entrevistas, no método clínico piagetiano e, para a análise das falas dos professores, usa elementos da metodologia de análise de conteúdo. Ela pretende apreender noções epistemológicas, subjacentes às respostas dos docentes. Afirmações emblemáticas, sob o ponto de vista epistemológico, dos entrevistados são utilizadas para 
subtítulos. Docentes expressam suas concepções epistemológicas ao falarem do desenvolvimento cognitivo de crianças e adolescentes, de questões educacionais ou de sua compreensão do processo de aprendizagem e de ensino. A presente análise debruça-se sobre as respostas dos docentes às questões 4 a 8:

4) A partir de que idade o aluno pode aprender a matéria que ensinas?

5) E antes dessa idade, por que não aprende?

6) Com sete anos a criança pode aprender álgebra?

7) Com três anos a criança pode aprender aritmética?

8) O recém-nascido apresenta noções matemáticas?

A análise das respostas dos docentes às 24 questões está programada para ser desenvolvida em sete blocos, agrupando as questões: a) de 1-3 (concepção de conhecimento matemático, já publicada); b) de 4-8 (gênese de noções matemáticas elementares - texto atual); c) de 9-11 (concepções de aprendizagem e de ensino de Matemática - em análise); d) de 12-14 (capacidade de aprendizagem, herança genética e meio social); e) de 15-19 (valorização, pela docência, da História da Matemática); f) de 20-23 (significado atribuído por alunos e professores à Matemática ensinada na escola, à tabuada e ao uso de algoritmos); g) de 24-25 (currículo escolar, mudanças no ensino de Matemática e funcionamento das salas de aula nesse ensino) acrescida de observações de sala de aula. Cada bloco analisado gerou ou gerará um artigo e visa, sob uma ótica particular, a busca do objetivo geral da pesquisa - como acontece com a presente análise - que é o levantamento das concepções epistemológicas dos docentes de Matemática.

A intenção da análise atual é saber em que etapa da vida humana os docentes situam o surgimento das noções matemáticas que julgam necessárias para que o sujeito humano possa começar a pensar matematicamente e o aluno a compreender conteúdos matemáticos ensinados e a que eles atribuem sua gênese. A sucessão das perguntas visa desestabilizar concepções epistemológicas de senso comum, empiristas ou aprioristas, e descobrir a que concepção epistemológica o professor recorre para contornar as contradições que vivencia. Em outras palavras, busca saber o que eles "inventam" para superar os impasses epistemológicos enfrentados e que concepções epistemológicas subjazem a essas "invenções" ao afirmarem que as noções matemáticas básicas resultam da pressão do meio físico ou social (empirismo), ou já vêm formadas no genoma, mas só aparecendo nos primeiros anos de vida por força da maturação biológica (apriorismo), ou resultam da ação do sujeito que abstrai de suas coordenações de ações (PIAGET, 1995) as referidas noções, construindo-as em patamares sucessivos de complexidade crescente. Os docentes, cujos nomes são ordenados alfabeticamente, serão nomeados por algarismos, de 1 a 17, precedidos da letra $\mathrm{P}$ (Professor); 
dessa forma preserva-se o anonimato. Evitou-se indicar a nacionalidade por ser desnecessária à pesquisa e para tornar improvável qualquer identificação. A análise organiza as falas dos docentes em duas categorias básicas, de acordo com as epistemologias clássicas (empirismo e apriorismo), e uma terceira, entendida como superação delas, representada aqui, pelo construtivismo piagetiano; mas, as subcategorias, expressas nos subtítulos, emergem da análise minuciosa das falas dos docentes.

Desde já o pesquisador agradece, de coração, aos docentes entrevistados pela disponibilidade e generosidade ao responder às entrevistas; sem elas, a pesquisa seria impossível.

A referência teórica básica é a Epistemologia Genética piagetiana.

\section{Empirismo}

Como vimos em pesquisas anteriores (BECKER, 2016; 2012), a concepção empirista é recorrente e dominante na docência em geral e, também, na docência de Matemática. Como os números não existem na natureza, pois não se abstraem dela os números, pensar-se-ia que a visão empirista do conhecimento matemático seria impossível. Não é o que acontece, como veremos a seguir, visto que os docentes não pensam que as operações matemáticas se originam das ações humanas, ou das coordenações das ações, sobre a natureza, por abstração reflexionante (PIAGET, 1995).

\section{1 "A matemática está presente em tudo!"; "a linguagem já é matemática"}

Acompanhemos P2, professor universitário de Matemática Pura. Para ele, os alunos podem aprender a Matemática que ensina com 19 ou 20 anos de idade, pois eles "têm uma bagagem de conhecimento" (pré-requisito). Concorda que com menos idade também podem aprender. Pergunta-se: "E com cinco anos?" Surpreende ao afirmar: "Cinco não; antes, muito antes. Acho que [podem aprender] $]^{1}$ toda a aritmética, a geometria; álgebra, não. Com cinco anos acho que é difícil aprender álgebra. Mas geometria e aritmética sim, com certeza. Os números".

\footnotetext{
${ }^{1}$ Usaremos colchetes sempre que for necessário completar o texto para salvaguardar a compreensão ou três pontos entre colchetes $-[\ldots]$ - para suprimir parte da fala. Faz-se isso com extremo cuidado para não modificar seu sentido.
} 
Surpreende ainda mais quando afirma que podem aprender com três e até com dois anos, pois: "A linguagem já é matemática"). Mas, quando se pergunta se o recém-nascido tem alguma noção matemática, responde: “Não, não, não". Pergunta-se: "Então, de onde vêm as noções matemáticas?” Ele responde: "Da natureza. Estão na natureza”. "Como é que chegam à cabeça do bebê, ou da criança pequena?” Ele afirma, com surpreendente convicção: “O que a gente tem na cabeça [...] são círculos, linhas, pontinhos, coisinhas". Retruca-se, então: "Mas não existe um círculo na natureza!” Diz ele: “Não existe! É incrível! Mas esta é a capacidade de abstração que tem o ser humano. Desde criança, você já percebe que ele... [estala os dedos, indicando que esse humano teve um insight] compreende". E acrescenta: "A linguagem, então, coisa muito mais complicada ainda!". Surpreso, o entrevistador desafia: "Se abstrair é tirar alguma coisa de..., de onde é que a criança tirou o círculo, se na natureza não existe círculo?” Ele responde:

Porque para ela [a criança] parece um círculo e a mente [apreende] o que faz parecida uma coisa com outra. A mesma coisa [acontece] com os conjuntos; com os números. Este conjunto parece com este conjunto; em que se parece? [Aquele] tem dois, e este tem dois. (E acrescenta:) "Ela [a criança] tem dois anos e [...] já consegue entender quem tem um [objeto] e quem tem dois [objetos] (Entrevista com P2, 2014).

Tudo indica que a abstração de que ele fala não é a pseudo-empírica (BECKER, 2014; 2017), modalidade da reflexionante (PIAGET, 1995), mas a empírica. Ele afirmou que as noções matemáticas estão na natureza e, também, na linguagem; urge abstraí-las de lá. Mas falta algo, isto é, um a priori. Ele explica: nós temos na cabeça “círculos, linhas, pontinhos, coisinhas" - eis o a priori. Será que ele quer dizer que a mente vem formatada para poder abstrair a Matemática embutida na natureza e na linguagem? É o que parece. Se a interpretação for correta, para ele as noções matemáticas seriam adquiridas por abstração empírica tal como se abstraem, mediante percepção, características materiais do mundo físico - cor, densidade, peso (sopesar), grandeza - o que configuraria claramente um empirismo. Seu apriorismo, que postula a herança mental de círculos etc., viabiliza seu empirismo: a criança reconheceria um círculo porque o compararia com o círculo que tem na cabeça desde seu nascimento, configurando um platonismo. Segundo Piaget (1993), somente a partir dos 4 anos de idade, a criança começa a diferenciar as formas geométricas euclidianas; e sua compreensão será plenamente acessível somente no período das operações formais, portanto, na adolescência.

Após conceder que alunos, com idade de 15 a 17 anos, podem aprender a Matemática que ensina, P13, docente universitária, afirma que as crianças podem aprender com dez anos e admite que, com sete não será fácil. Exemplifica com sua filha de dois anos para quem diz: 
[...] vamos armar uma torre de 7 pisos. Ela me diz: "7?" E eu lhe digo, "Sim". E vou the ensinando. E [ela] vai contando. Lhe digo: "Conta quantos vamos almoçar". "Mamãe, 2!" [Digo:] "Então tu pegas dois garfos, duas facas...". Mas, vou lhe repetir: a matemática está presente em tudo. Pergunta-se, então: "Quando começaram, na tua filha, as noções matemáticas?" Ela responde: "Um ano e meio, mais ou menos". E acrescenta que ela não tinha, ao nascer, noções matemáticas. Então: "De onde vieram essas noções?" Ela responde: De ir lhe inculcando e dizendo: duas pessoas vão comer, quantos talheres necessitamos? Faça uma torre de três pisos! Quantos pés tens? Quantas mãos tens? Quantos dedos tens em tuas mãos? Tudo vou lhe dizendo. Quantos dedos tens ao [ao todo]? E lhe digo, vá contando. Tem dois anose vai contando (Entrevista com P13).

Pergunta-se: "A compreensão matemática dela vem do esforço que ela faz para compreender os problemas ou do estímulo que dás a ela?” Responde que acredita que seja do estímulo. E arremata: "Esta é a melhor maneira, eu creio, de praticar. Não sei”.

\section{2 "Creio que quando nasce não sabe nada. Incorpora tudo depois"}

P6, docente universitário, informa que leciona Estatística Matemática. Pergunta-se: se ele ensinasse esse conteúdo a crianças de sete anos, elas aprenderiam? Diz que não sabe, não acredita. Mas que se pode "ter as ferramentas que lhe ajudem a compreender mais rápido essas coisas ou pelo menos a se familiarizar com elas e a incorporá-las em sua própria vida". Em seguida, afirma que não entenderiam porque aquilo que ele entende por compreender a criança não consegue, pois "não compreende nada, não somente matemática". As crianças "estão acabando de entrar neste mundo e estão vendo como é tudo, ou seja; não apenas [não compreendem] a matemática, penso que em geral", ou seja, acredita que não compreendem as coisas. A seguir, parece superestimar as capacidades infantis ao dizer: "[...] claro que as crianças se acostumam a ver nos jornais as estatísticas de futebol, por exemplo, e vão começando a incorporar nem que seja uma palavra ou um conceito; mas não entendem realmente, profundamente. Nem isso, nem muitas outras coisas".

“E uma criança de 4 anos, o que poderia compreender de Matemática?” Responde ele: “Não sei. Tenho uma filha de 3 [anos] e, hoje, ela está aprendendo a repetir os números: 1, 2, 3”. Pensa que, nessa idade, as crianças “[...] vão acompanhando os números naturais e, talvez, um pouco de frações. Ou seja, tenho uma torta e somos sete e tenho que parti-la em 7 pedaços. De maneira básica, mas vão começando a incorporar". Segundo ele, algo parecido acontece com crianças de sete anos de idade já que elas “... começam a incorporar coisas, não que as compreendam profundamente, mas começam a compreender". Afirma que com ele também acontece isso, pois após trabalhar dez anos nessa área, “... sinto que entendo algo mais; que entendo melhor". 
Diz não acreditar que recém-nascidos possam aprender algo: “Creio que quando nasce não sabe nada. Incorpora tudo depois". Pergunta-se: "De onde vêm as primeiras noções matemáticas?" Afirma ele que elas aparecem com dois ou três anos de idade, "quando elas começam a contar. Contam mamãe, papai: 1, 2. A família: mamãe, papai, primeira irmã, segunda irmã, eu = 5. Para mim, as primeiras noções são assim”. Acredita que, por primeiro, aparecem os números naturais; "eles seriam as primeiras noções matemáticas da criança". Mas, dividir uma torta, "isso é mais elaborado, isso é para os maiores".

Tudo indica que P6 professa um empirismo próximo ao de Locke (1632-1704) que retoma a formulação de Aristóteles (384-322 a.C.) ao afirmar que nada há em nossa mente que não tenha passado antes pelos nossos sentidos. Para ele, o humano, ao nascer não sabe nada, "incorpora tudo depois"; os recém-nascidos "vão começando a incorporar". As primeiras noções aparecem quando a criança começa a contar: mãe + pai + irmã + segunda irmã... "Para mim, as primeiras noções são assim". Além de atribuir à criança uma insustentável e precoce noção de número, atribui à criança dessa idade uma consciência que ela levará anos para adquirir; consciência de que, se ela tem um irmão, esse irmão também tem um irmão, ou irmã, que é ela.

\section{3 "É um pouco de repetição. [...]. O primeiro trabalho eu acho que é a repetição"}

P1 ensina Cálculo para ingressantes na Universidade. À pergunta: “A criança, com sete anos, pode aprender Aritmética?", ela responde: "Está acostumada a somar maçãs com maçãs e peras com peras. Eu creio que, num nível baixo, poderia". "E com dois anos?" Não creio. "Que capacidade matemática teria uma criança de 2 anos?" "Creio que, com sorte, sabe os números. Mas apenas os diz, não sabe o que significam". "E recém-nascida?" Sorri e afirma peremptória: “Impossível!’. Pergunta-se, então, "Mas como este recém-nascido, daqui a 7 anos, conseguirá somar, subtrair? O que acontece, do nascimento aos 7 anos?". Responde: "É um pouco de repetição. [...]. Primeiro trabalho eu acho que é a repetição". "E a repetição leva ao significado? Ou tem que entender o significado antes de repetir?", ao que afirma: "Eu creio que faz as duas coisas [diz ela]. Elas trazem na cabeça, por exemplo, que o número um corresponde a apenas um elemento e o veem várias vezes. Talvez entendam antes".

2.4 O "que estamos vendo agora, são de acordo com sua idade"; "Eles não entenderiam" porque "teriam que ter passado por conhecimentos de propriedades, de operações..." 
P11 leciona para alunos de 12 a 13 anos de idade. Afirma que, com dez anos, eles não aprenderiam porque os conteúdos "que estamos vendo agora, são de acordo com sua idade". "Eles não entenderiam" porque "teriam que ter passado por conhecimentos de propriedades, de operações [...]; ou, ainda, que tenham conhecimento de alguns conceitos bem aprendidos para compreender". Aqui, a docente atribui a incapacidade de aprendizagem dos referidos conteúdos, não à idade, mas à falta de pré-requisitos. Com sete anos, a criança teria capacidade de "seriação, de racionalização lógica, mas mais para o concreto". Com cinco, demonstraria capacidade para o simbólico e o concreto; com dois anos, poderia aprender "formas como se colocam no espaço ao redor; calcular qualitativamente distâncias - quantos passos ela terá que dar para pegar tal objeto". "Mas, aos dois anos, não tem ideia concreta dos números, de quantidade, somente [capacidade de] formar figuras e símbolos". Já o recém-nascido tem capacidade de observação "não muito aguda, não muito desenvolvida". "Tem que se adaptar para que, pouco a pouco, vá reconhecendo cores, as formas dos rostos". Mas nenhuma noção matemática.

P12 diz que o curso que ministra na universidade é de Matemática Básica. Ministrará matrizes que "alguns alunos não fazem ideia do que se trata". Pergunta-se a ela se crianças de dez anos de idade aprenderiam matrizes. Ela acredita que sim, pois se ensinam a crianças dessa idade certas operações como regras de jogo. Porém, com sete anos acredita que não. Pensa que a criança ao nascer não traz noções matemáticas pois só “querem agarrar, pegar coisas para si mesmas".

Pergunta-se, então: "Se nada tem ao nascer, quando é que vão aparecer as primeiras noções matemáticas?". Noções de forma, de objetos, “ao tocar as coisas que a rodeiam". Pergunta-se: “Quando a criança conta, ela já tem a noção de número?”, diz que não; que ela "pode contar com os dedos, sem ter a noção de 1, 2". A noção de número surge, segundo ela, aos quatro anos, mas não especifica em função de que; infelizmente, não lhe foi perguntado.

Essas professoras consideram que a criança não herda qualquer noção matemática; tudo tem que ser aprendido. Dão a entender, se bem interpretamos, que todas as noções matemáticas que ela adquire vêm do ensino, formal ou informal. Para que aprenda qualquer conteúdo novo, a condição é que tenham sido ensinados a ela os pré-requisitos na idade certa e que ela os tenha aprendido. E a aprendizagem ocorre por repetição.

\subsection{A predominância empirista}


Das nove falas analisadas (P1, 6, 7, 9, 11, 12, 13, 16 e 17) nesta seção, apresentamos apenas seis (P1, 2, 6, 11, 12 e 13); mas as três restantes comparecem nas sínteses parciais e nas Conclusões. Essas falas manifestam concepções epistemológicas claramente empiristas. A maioria não acredita numa tábula rasa propriamente dita, tal como propõe o empirismo clássico, formulado por Locke; postula algum a priori como a maturidade, o cérebro ou "cerebrozinho" ou os "círculos, linhas, pontinhos, coisinhas", a partir do qual as instâncias do meio, como a transmissão pelo ensino escolar ou informal, a estimulação ou a inculcação, seguidos de incorporação por repetição, deixarão sua marca. Os que pensam assim são mentores de um empirismo não radical; empirismo que se legitima por um certo apriorismo epistemológico, sustentado por um inatismo biológico atribuído à maturação.

Alguns (P1, P11, P16 e P17) aproximam-se de um empirismo radical quando afirmam que tudo depende da inculcação ou estimulação e da repetição; empirismo que concebe que o recém-nascido nada sabe, não traz qualquer capacidade matemática; incorpora tudo depois do nascimento.

Portanto, uns e outros explicam a origem do conhecimento matemático de um indivíduo humano pela ação do meio sobre um sujeito (quase) passivo.

Todos, de uma ou outra forma, admitem um a priori geral, a maturidade ${ }^{2}$; mas, acreditam principalmente no poder do meio de determinar o sujeito. Porém, para que o meio possa exercer sua influência, deixar sua marca, o organismo precisa estar maduro. Isso parece explicar uma série de crenças dos docentes a respeito das possibilidades de aprendizagem, tais como: ao nascer, o bebê nada tem, quando abre os olhos vê tudo, sabe que esteve encapsulado num espaço pequeno e, quando sai, "pensa” que está num espaço maior; recém-nascido não aprende porque não tem linguagem; com dois anos, a criança relaciona coisas, quantitativamente, quando diz meu, teu, grande, pequeno; com essa idade, ela já compreende quem tem $u m$; as crianças mostram capacidade de observação e tudo que observam, aprendem; já poderiam aprender soma e subtração com pequenas quantidades; são intuitivas, sabem diferenciar, classificar, mas sem rigor; poderão talvez diferenciar bolas, cubos, formas; a noção de número começa com três, dois e, até, um ano e meio, "pois a linguagem já é matemática"; podem, de forma primitiva, aprender a contar, a quantificar, a ter a intuição do que é um número; com três anos podem repetir os números 1, 2, 3; acompanhar os números naturais e, talvez, frações - uma torta e sete pessoas terá que ser repartida em sete fatias, assim vão começando a

\footnotetext{
2 Termo sem definição precisa que não distingue desenvolvimento biológico de desenvolvimento psicológico e cognitivo. Herdado do senso comum faz pressupor que desenvolvimento biológico, psicológico, cognitivo e moral resultam de um mesmo processo, o de maturação biológica. Esse termo carrega um conteúdo sincrético.
} 
incorporar; contam (mãe, pai = 2; ou mãe, pai, irmão, irmã, eu = 5), aparecem assim os números naturais que são as primeiras noções matemáticas; com quatro anos, a criança conseguiria contar formalmente; muito antes dos cinco anos podem aprender os números, aritmética, geometria, mas não álgebra; com cinco anos, se simplificar o conteúdo, aprende, aliás, está sempre aprendendo; com dois anos, se lhe falta um brinquedo, ela sabe, se há várias coisas e se tira uma, ela se dá conta, está ali a ideia de número.

Como se vê, a maturação é uma instância explicativa sincrética que pode justificar qualquer aprendizagem em qualquer idade porque, em última instância, o meio determina, mas é usada também para explicar as não aprendizagens - essa criança não aprende tal conteúdo porque é imatura, dizem docentes. Não aparecem escalonamentos maturacionais, fases, etapas ou estádios de maturação. As noções matemáticas surgem de ir inculcando nas crianças, da estimulação; elas vêm da natureza, pois estão na natureza, não apenas do meio social. A estimulação é poderosa pois já determina o feto, como acontece com a música ouvida pela gestante. Tudo depende da estimulação que o adulto proporciona. Mas, paradoxalmente, a estimulação precisa de um a priori, a maturação, e de um auxiliar, a repetição.

Estimulação e maturação seguidas de repetição são instâncias explicativas vindas do senso comum tão pouco refletidas pela docência que, à menor perturbação, provocada pelas perguntas da pesquisa, sofrem abalos profundos. Para fugir da contradição passa-se a atribuir, por exemplo, a diferença na capacidade de aprendizagem de chimpanzés e crianças não mais à estimulação ou inculcação, mas à complexidade do cérebro (P6); ou, ainda, temos na cabeça "círculos, linhas, pontinhos, coisinhas" (P2) que possibilitam o conhecimento matemático.

\section{Apriorismo}

\subsection{As crianças "vêm com um certo legado dentro de seus neurônios"}

P8, em vez de responder à pergunta: "Com que idade pensas que as crianças podem aprender o que ensinas?”, faz críticas ao sistema de ensino de sua escola. O interesse dessa crítica reside em sua compreensão a respeito do que o ser humano traz de Matemática, ao nascer. Diz ele que discorda da atual programação, exemplificando:

[...] estudei valor absoluto e funções no superior. Aqui, passou-se a ensinar no quarto ou quinto ano da educação secundária; agora, ensina-se no primeiro ano. E eu não vejo sentido, os alunos não me entendem... não assumem um valor absoluto [...]; em seu "disco" [rígido] não há esse valor. A disciplina de funções na universidade é onde mais há reprovações, porque o entendimento da definição de funções não é [fácil] (Entrevista com P8). 
Perguntado sobre a capacidade de aprender Matemática com cinco anos de idade, o professor responde: "Eu tenho a impressão de que os conteúdos não teriam que estar circunscritos a questões de tabelas e números. Teria que ser uma atividade mais baseada em jogos...". Justifica sua afirmação dizendo mais ou menos o seguinte: assim como a humanidade aprendeu a escrever, assim também aprendeu Matemática. Quando isso começou na evolução, os adultos eram mentalmente crianças. Temos que tratar as crianças como seres evolutivos, “... e encontrar coisas que se possa utilizar, que estejam em seu 'disco rígido' [cérebro], para usá-las sempre”.

P8 pensa que crianças de dois anos já têm alguma noção matemática. Cita autores que fizeram estudos observando seus netos, para exemplificar com sua neta de dois anos; diz que a observou "relacionando coisas", quantitativamente, com "meu, teu”, "grande, pequeno". Ele afirma sua convicção de que as crianças "vêm com um certo legado dentro de seus neurônios". Não especifica, porém, que tipo de legado é esse; infelizmente, não lhe foi perguntado a respeito. À pergunta: “O que o recém-nascido traz de Matemática?”, começa respondendo com uma sonora risada. Acrescenta, então, que "Cada vez é mais possível que, com a ressonância magnética, se possa descobrir" por que as crianças aprendem tão rapidamente a ponto de não podermos afirmar que elas nascem sem nada de Matemática. "Eu acho que sim, que já têm algo incorporado ao seu 'cerebrozinho"'. Pergunta-se: "De conteúdo ou de capacidade?". "De capacidade, definitivamente. Eu acho, honestamente, que [elas] trazem de capacidade, mas que as outras funções mentais, essas têm que aprender, vão se desenvolvendo também".

Resumindo: o docente pensa que o ser humano nasce já formatado para a Matemática, pois, ao nascer, já traz algo de Matemática em seu cérebro, em seus neurônios. A outra parte o ensino deverá realizar, mas, para isso, deverá encontrar elementos no "disco rígido" ou no cérebro dos alunos, elementos que o docente deverá utilizar sempre; a docência não logrará sucesso se ensinar algo sem poder contar com o valor correspondente nesse "disco". Ensinar "valor absoluto" é difícil porque nesse disco rígido não há esse valor. Confirma seu apriorismo ao dizer que as crianças "... vêm com um certo legado dentro de seus neurônios" e acrescenta que, com a ressonância magnética, descobriremos por que as crianças aprendem tão rapidamente a ponto de termos que admitir que elas nascem com "... algo incorporado ao seu cerebrozinho"; com algo de capacidade matemática, não de conteúdo. 


\section{Simbiose empirismo \& apriorismo; maturacionismo}

Os docentes professam, em geral, uma epistemologia empirista ao responder às perguntas sobre a natureza e a origem do conhecimento ou das capacidades cognitivas (BECKER, 2019) como também sobre a capacidade que têm seus alunos para aprender o que ensinam. Assim que se regride na idade, perguntando-se sobre as capacidades cognitivas de crianças de sete, quatro, dois anos, recém-nascidas, as convicções empiristas começam a desmoronar dando lugar a várias formas de apriorismo (como já vimos em forma mais branda na subseção 2. e em forma mais radical na 3., acima). Às vezes misturadas com concepções empiristas, outras vezes em forma de apriorismo quase puro. A seguir, examinaremos as falas dos docentes do ponto de vista do seu apriorismo e verificaremos como suas falas coordenam essas concepções com sua prática pedagógica, fundada no empirismo.

\section{1 "Há níveis de maturidade distintos"; "Na realidade, todos nascem com certa habilidade matemática"}

P10 leciona para oitavo ano, para crianças de 11 a 12 anos de idade, em escola que atende predominantemente classe média. Ele acredita que "Há níveis de maturidade distintos". Para confirmar sua crença, diz que compara alunos do primeiro e segundo anos do Ensino Médio com os de oitavo ano. Para uma criança aprender o que se ensina para o oitavo ano, "vai depender do nível de maturidade que tenha". Por isso, crianças de sete anos não poderiam aprender tais conteúdos porque não teriam atingido o nível de maturidade necessário; às de três anos, faltaria muita maturidade. Sobre o recém-nascido, afirma: "Na realidade, todos nascem com certa habilidade matemática". Mas vai depender de como se ensina Matemática para que o conhecimento ou a habilidade matemática vá se desenvolver. Pergunta-se ao entrevistado: "É maturação ou desenvolvimento?” Diz ele: “Tem a ver um pouco com maturação que vai tendo; quanto maior [de mais idade] a pessoa, maior a capacidade para poder entender".

Pergunta-se, então: "Por que uma criança de cinco anos não aprende álgebra?" Porque a álgebra é mais complexa de se compreender com relação a outros conteúdos matemáticos: “Bom, pelo menos eu sempre sou partidário que um pouco mais complexo de ver, em relação a tudo, é a álgebra".

Eu sei que não vão ver um x caminhando [por ali], mas podem ver números [...]; quando eu generalizo isso, como variável, é difícil para a criança racionalizar. Uma criança de 5 anos vai ter dificuldade, por sua habilidade [para compreender] para poder transformar toda a matemática em variáveis ou em letras (Entrevista com P10). 
A culpa da não aprendizagem de álgebra, pelos alunos é, segundo ele, da docência. Justifica dizendo que os professores sempre dão exemplos com números. Ao fazer isso, o docente cria um problema: não faz o aluno "... pensar para que generalize as coisas". O professor não leva o aluno a generalizar, imaginar o que pode acontecer com exemplos numéricos, com figuras geométricas em geral. Com números, levar o aluno para o $x$ da questão. É claro que o aluno sempre vai entender o $x$ da questão com números. O problema começa quando se mostram letras. Mas, esse problema é de quem ensina, “... pois quem ensina tem que explicar primeiro o que são variáveis, [para] que já conheçam o termo variável, que consigam imaginar valores que essas variáveis possam ter".

Esse docente considera que a condição da aprendizagem de Matemática é fornecida pela maturação que se revela com a idade. Não relaciona maturação e desenvolvimento cognitivo porque os condensou num único fator: a maturação. Quando atribui ao aluno a responsabilidade de generalizar - o que o levaria ao desenvolvimento cognitivo - imediatamente desvia para o ensino essa responsabilidade, como se o aluno precisasse apenas de maturação e ensino para generalizar e, consequentemente, compreender álgebra.

Para Piaget (1972), a maturação é condição necessária ao desenvolvimento cognitivo e, portanto, à aprendizagem. Porém, de forma alguma, suficiente. Somam-se à maturação a experiência, física e lógico-matemática, a transmissão social (ensino, por exemplo) e a equilibração; esses, com destaque ao último e regulados por ele, são fatores suficientes do desenvolvimento cognitivo e, consequentemente, da aprendizagem. O trânsito de um estádio a outro do desenvolvimento pode ser caracterizado por uma cronologia. Piaget (1973, p. 50) alerta que “[...] essa cronologia é extremamente variável; ela depende da experiência anterior dos indivíduos, e não somente de sua maturação, e depende principalmente do meio social que pode acelerar ou retardar o aparecimento de um estágio [estádio], ou mesmo impedir sua manifestação".

O docente também articula pouca relação entre seu apriorismo ("todos nascem com certa habilidade matemática") e as dificuldades dos alunos de generalizar as relações aritméticas para pensar algebricamente. Piaget (1978b) afirma que a generalização é o destino “natural” da abstração reflexionante (PIAGET, 1995); uma e outra são tributárias da maturação, mas, jamais se reduzem a ela; são instâncias construtoras das operações. 


\subsection{Herdamos "uma matemática básica e universal, a partir da qual se constrói todo o resto"; a capacidade de aprender "É um pouco inata"; "há pessoas que têm mentes brilhantes, mas são poucas"}

P14 diz que a matéria [Transformadas de Fourier] que ensina destina-se a alunos do final da licenciatura; ela exige que o aluno tenha "[...] uma boa maturação matemática. Que tenha feito pelo menos um ou dois anos de matemática universitária, com um bom curso". É capaz de aprender essa matéria "[...] um aluno de 18 anos, se for super capaz; ou [de] 15 e 16 anos, se tiver mente privilegiada". Pergunta-se, então: "Esta capacidade de aprender aparece quando?". Responde ele: “É um pouco inato; é verdade que treinamento fortalece e melhora as estratégias. Pode-se desenvolver muito, como a música, o futebol. Se [tiver] talento inato e depois as boas estratégias para adquirir novos conhecimentos". À pergunta: "Somente algumas pessoas nascem com essa capacidade?", ele confirma:

Evidentemente, há pessoas que têm mentes brilhantes, mas são muito poucas. Isto, sem dúvida, não se arruma trabalhando muito; arruma-se com muito talento e sorte, mas é certo que pessoas com capacidade racional podem melhorar muito com boa aprendizagem; [a capacidade matemática] pode ser uma mistura [de talento e aprendizagem]. Como todas as atividades na vida, não existe nenhuma que não seja assim. Com escrita e literatura também penso que seja igual; não acredito que seja muito diferente. Pode-se dizer que na matemática é assim, a pessoa pode ter certeza quase absoluta (Entrevista com P14).

Sabendo que a formação do entrevistador é filosófica, ele diz: "Você sabe melhor que eu [...] sobre o fundamento da matemática [que] é a lógica, que permite que a matemática nunca esteja completamente fechada e perfeita. [...] comparado com o resto do conhecimento humano eu diria que a matemática é o [conhecimento] mais perfeito de todos. Essa é a diferença e nada mais". Reitera dizendo que acha que as duas instâncias - o talento (inato) e a aprendizagem (esta, patrocinada pela educação e pelo ensino) - são responsáveis pelo conhecimento matemático de um indivíduo.

Pergunta-se, então, se as pessoas nascem com a base cerebral para a Matemática ou "o talento inato". Ele confirma: “[...] evidentemente, as pessoas nascem com certa capacidade, mas se tiver um acidente, pode-se perder esta capacidade, e se não se ensinar suficientemente, não vão poder projetar esta capacidade”. Ele insiste, pois, na necessidade das duas instâncias, talento inato e aprendizagem patrocinada pelo ensino; mas, ao tentar esclarecer em que consiste a capacidade herdada, seu discurso torna-se mais hermético; aparentemente na linha de Chomsky, da gramática herdada:

[...] a pessoa nasce com uma matemática universal inata, isto estou certo; a estrutura matemática é fina. Estou tratando somente a estrutura matemática que não se adequa, vai resultar incômoda a mim e aos meus colegas. Quando um assunto é incômodo a todos, de certo 
modo existe uma desconexão com a estrutura, com a gramática que já está impressa no cérebro com a linguagem (Entrevista com P14).

Confirma, pois, a tese de Chomsky (1979b) de que herdamos geneticamente " $a$ gramática que já está impressa no cérebro, com a linguagem”. Isto é, segundo ele não só se herda uma base matemática, mas, também, uma base para a linguagem: uma gramática universal. Pode-se interpretar, aqui, que ele acredita que se herda geneticamente uma capacidade lógica básica, que vem impressa no cérebro do recém-nascido, tanto para a Matemática quanto para a linguagem (a gramática), a música etc. Ideias sobre a linguagem, parecidas com essas de P14, já apareceram em P2 e P16.

O entrevistador havia assistido, pouco antes da entrevista, à aula do entrevistado na qual ensinara as Transformadas de Fourier. Fazendo uma conexão entre a aula do docente e o que ele acabara de afirmar na entrevista, pergunta: "Por que, então, essa matemática não aparece na maioria dos comportamentos ou na formação geral de uma pessoa?" Ele responde, coerente com o que já afirmara sobre aprendizagem: "Isso [...] requer uma quantidade de informação e treinamento"; segundo ele, a capacidade lógica herdada é complementada pela informação e pelo treinamento.

Em vez de informação e treinamento, possibilitados pela capacidade lógica herdada, ele fala em complementados pela capacidade lógica. Isso sugere uma espécie de acumulação, e não de síntese como propõe Piaget em sua teoria da equilibração (PIAGET, 1977a) ou de abstração reflexionante (PIAGET, 1995; BECKER, 2019).

As convicções desse docente levam-nos ao "Debate entre Jean Piaget e Noam Chomsky" (1979b). Podemos flagrar as posições opostas desses dois pensadores nas seguintes passagens:

Diz Piaget (1979b, p. 53):

Cinqüenta anos de experiência nos ensinaram que não há conhecimento resultante de um simples registro de observações, sem uma estruturação devida às atividades do sujeito. Mas também não existem (no homem) estruturas cognitivas a priori ou inatas: somente o funcionamento da inteligência é hereditário e engendra estruturas apenas pela organização de ações sucessivas exercidas sobre os objetos. Como resultado, uma epistemologia em conformidade com os dados da psicologia não pode ser empirista ou pré-formista [apriorista], mas só pode consistir em um construtivismo, com a elaboração contínua de novas operações e estruturas. O problema central é, então, entender como tais criações ocorrem e por que, embora resultantes de construções não predeterminadas, elas podem se tornar logicamente necessárias (Tradução do autor).

Por sua vez, afirma Chomsky (1979b, p. 86-87):

Não vejo razão para duvidar de que também existam capacidades inatas de alto grau de especificidade que determinam o desenvolvimento de estruturas cognitivas, das quais algumas permanecem inconscientes e além dos limites da introspecção, enquanto outras, de um tipo provavelmente muito diferente, são explicitamente enunciadas e testadas. Nossa ignorância nessa área é imensa, mas não é impossível 
que os resultados da investigação de domínios cognitivos, relativamente bem definidos como a linguagem, sugiram um modelo eficaz para investigações mais aprofundadas (Tradução do autor).

O docente retoma sua ideia de que a Matemática é possível porque herdamos geneticamente uma base matemática que marca a estrutura do cérebro do recém-nascido, "uma matemática básica e universal, a partir da qual se constrói todo o resto, e o resto nos chega a partir da cultura". Ele vê clara similaridade com o que acontece com a linguagem; todos os seres humanos herdariam geneticamente uma gramática que se manifestaria na linguagem, na fala; e, correndo o perigo de extrapolar o que ele disse, também no pensamento matemático. "Uma criança aprende o seu idioma e, evidentemente, o idioma que ela aprende depende da cultura em que está".

Todos trazem essa herança, todos nascem com linguagem, mas a forma de aprender vai ser muito diferente de um para outro indivíduo. Isto é, poucos conseguirão "escrever poesia como Fernando Pessoa". Na Alemanha será mais fácil ser poeta como Goethe, ou na Inglaterra como Henry - a educação e a cultura possibilitam efetivas aprendizagens nesses países. Retruca-se que pesquisas psicogenéticas mostram que a noção de número aparece somente por volta dos sete/oito anos de idade; raramente antes dessa idade. "[...] o número surge como a síntese da classe e da relação assimétrica, ou, o que vem a dar no mesmo, da relação simétrica (igualdade) e das diferenças (relações assimétricas)" (PIAGET; SZEMINSKA, 1975, p. 331). Surpreendentemente, P14 não estranha; ao contrário, afirma que a linguagem também; ela "não aparece na idade zero", pois, de algum modo, “... o sistema nervoso não está maduro suficientemente, mas digo que o 'hardware' está ali". O entrevistador pergunta: "Hardware?". Ele confirma: "Hardware, como se fosse um computador. Este não depende de um programa que se coloca".

A concepção epistemológica de P14 complementa seu apriorismo com empirismo na formação do conhecimento matemático. Ela não chega a perfazer um construtivismo já que este supera dialeticamente a ambos. Esse docente concebe a capacidade matemática como originária de uma herança biológica que o indivíduo traz; uma "matemática básica e universal" que está no cérebro do recém-nascido e "a partir da qual se constrói todo o resto"; isto é, os conteúdos da cultura, incluindo nesse termo toda as criações e invenções humanas. Trata-se de um "talento inato" que o treinamento ou "as boas estratégias" poderão fortalecer seja na música, na escrita, na literatura, no futebol ou na matemática; afinal "todo mundo nasce com capacidades totalmente diferentes". A capacidade matemática, como qualquer coisa na vida, resultará de uma mistura de talento e aprendizagem. Essa concepção acredita que há (poucas) pessoas que 
têm "mentes brilhantes"; isso não é resultado de muito trabalho, mas de "muito talento e sorte"; tais pessoas "com capacidade racional" herdada, porém, "podem melhorar muito com boa aprendizagem"; isso implica ensino, pois "se não se ensinar suficientemente, não vai poder projetar esta capacidade", e pode até perdê-la.

A concepção epistemológica de P14 é marcadamente apriorista; seu empirismo, embora presente, é mero figurante nesse cenário. Entretanto, mais acredito do que tenho certeza, esse docente apresenta um terreno fértil para um construtivismo que supere, dialeticamente, sua concepção apriorista e seu complementar empirismo.

Como vimos, P10 e P14 diferenciam-se dos demais analisados na medida em que seu apriorismo é mais dominante, sem, entretanto, desautorizar seu empirismo. Por isso podemos falar de um relativo balanceamento, ou melhor, de uma simbiose entre apriorismo e empirismo.

Cabe, aqui, mais do que uma observação, uma proposta. Na formação de professores de Matemática, instaurar debates epistemológicos trazendo as informações da psicologia e da epistemologia genéticas, confrontando-as com as informações e reflexões da qualidade das manifestadas por esses docentes. Sairiam dali significativas contribuições para a didática da Matemática.

\title{
5 Construtivismo?
}

Coerente com a visão construtivista piagetiana, o filósofo E. Stein (2009, p. 40) concebe o conhecimento não como um processo pronto, acabado, sem relação com o mundo:

\begin{abstract}
Aprender não é receber pegando. Há um processo [...] ativo, que deveria estar expresso na questão da Aprendizagem. O Construtivismo pretende exatamente isso: fazer com que a linguagem (que é expressão da racionalidade humana), as frases (que é a expressão da capacidade de argumentar, de trazer razões) sejam o elemento que caracteriza o ser humano, e não mais uma razão abstrata, uma faculdade pronta, educadinha, bem alimentada. Nós não temos isso acabado, pronto. Recebemos isso através de um processo resultante da nossa interação com os outros (STEIN, 2009, p. 40).
\end{abstract}

P15, docente universitária, diz que praticava, no ensino, "um enfoque mais condutista"; mas, "[...] estudei para aprender o enfoque construtivista, com bases em Piaget". Sobre a capacidade matemática da criança de quatro anos, diz que "[...] tem que preparar esta mente mediante a percepção de cor, forma, tamanho, atenção à memória, que são processos cognitivos básicos para que a mente se prepare para poder entrar em conceitos matemáticos". É estranho seu construtivismo pois atribui à criança de quatro anos qualidades que Piaget (1978a; 1979a) localiza na formação dos primeiros esquemas do período sensório-motor, como a memória que aparece como assimilação recognitiva; e na formação dos esquemas 
secundários, senão antes, como diferentes formas de percepção que Piaget interpreta como atividades perceptivas. Ao afirmar que "uma criança de dois anos é ainda muito perceptiva", ela ignora toda a interpretação da Epistemologia Genética de que a criança é ativa desde o início. É difícil reconhecer, em suas afirmações, um construtivismo; muito menos um construtivismo piagetiano.

$\mathrm{P} 4$, professor universitário, pensa que apenas algumas coisas da disciplina que ensina para universitários de 18 a 20 anos poderiam ser aprendidas por indivíduos uns dois ou três anos antes, não muito mais, "se se puserem de lado alguns tecnicismos". Com menos idade do que estas, não poderiam aprender porque lhes falta certo "nível de pensamento formal que se adquire, segundo alguns teóricos, aos 11 ou 12 anos de idade". Justifica ainda porque "o nível de formalismo, que é bastante intrínseco aos temas que tu vais ensinar, têm que ser acessíveis". Tal formalismo seria, "em grande medida", indispensável para aprender essa Matemática.

À pergunta sobre a origem das capacidades matemáticas, ele responde criticando o ensino por se descuidar desse aspecto.

Tenho certeza de que nós trabalhamos pouco sobre as capacidades [...]. Na realidade, poderia pensar que algumas capacidades poderiam ser trabalhadas na escola, talvez não o manejo formal de certos recursos, mas, por exemplo, a resolução de problemas; resolver problemas é trabalhar com uma capacidade de desenvolver um [problema] antes que haja formalismo instaurado. Acredito que isso sim se poderia, se deveria [fazer] (Entrevista com P4).

Ele afirma nada saber sobre capacidades matemáticas do recém-nascido e pensa que “noções matemáticas" as crianças “desde muito pequenininhas” já podem aprender. Quando se insiste sobre o que os humanos trazem a respeito quando nascem, afirma que " $O$ que faz com que sejam possíveis [as capacidades matemáticas] é a interação com as pessoas. Ou seja, uma criança com outras crianças que já sabem outras coisas e com seus pais; o contato me parece imprescindível para que vá criando suas capacidades...".

Como se vê, apenas dois docentes podem ser incluídos nesta seção. Pensar e agir como construtivista implica superar concepções epistemológicas aprioristas e empiristas. P15 afirma assumir o construtivismo piagetiano, mas quase nada mostra que confirme isso. P4 não se assume como construtivista, mas mostra preocupação, própria de quem pensa em sintonia com a epistemologia construtivista; preocupa-se com "o nível de formalismo" que o aluno precisa ter atingido para compreender o "que é bastante intrínseco aos temas que tu vais ensinar", isto é, a complexidade dos conteúdos matemáticos que o aluno deverá aprender.

Segundo ele, o professor deve prestar atenção para saber se o aluno vem com "capacidades" que, se pressupõe, tenham sido "trabalhadas", quando na verdade não o foram; ou "tenham sido trabalhadas, mas os estudantes não as possuem"; não necessariamente "o 
manejo formal de certos recursos, mas, [...] a resolução de problemas" - "resolver problemas é trabalhar com uma capacidade de desenvolver um [problema], antes que haja formalismo instaurado". E arremata com uma preocupação genuinamente construtivista: "Acredito que isso sim se poderia, se deveria [fazer]". Embora poucos elementos apareçam em sua fala, que atestem uma posição construtivista, os que aparecem - o formalismo lógico necessário para aprendizagens mais complexas e a resolução de problemas para chegar a níveis de formalismo - são importantes para a concepção construtivista trazida para a construção escolar de conhecimentos.

\subsection{O que diz Piaget?}

Para Piaget, toda aprendizagem (BECKER, 2012a) depende de capacidades cognitivas do sujeito, previamente construídas por ele. Essas capacidades são lógicas. Elas originam-se pelo processo de desenvolvimento cognitivo (PIAGET, 1972) que ocorre pela atuação equilibrada dos fatores de maturação (biológica), experiência (física e lógico-matemática, esta abrindo possibilidades para aquela), transmissão social e equilibração. Originam-se as capacidades cognitivas na medida das ações do sujeito; ações possibilitadas pela maturação, mas nunca reduzidas a ela ou por ela explicadas; ao contrário, ações que se organizam em esquemas que se interiorizam em estruturas operatórias - estruturas ao mesmo tempo estruturadas e estruturantes (PIAGET, 1978a). Para Piaget (1977b), a ação tem êxito precoce com relação à compreensão; “[...] a ação em si mesma constitui um saber, autônomo e de uma eficácia já considerável” (PIAGET, 1977b, p. 207); é a tomada de consciência desse saber, iniciando pelos resultados, exitosos (PIAGET, 1978c) ou não, da ação até atingir seus mecanismos íntimos; é esse desenrolar das ações, seguidas de progressivas e crescentes tomadas de consciência, que conduz à formação de conceitos, ainda com reversibilidade parcial (período operatório concreto). Esse processo demanda tempo; no caso da noção de número vai do nascimento aos 7/8 anos de idade; no caso dos conceitos com incipiente reversibilidade completa, pelo menos 11/12 anos.

O surgimento do conhecimento matemático propriamente dito, que se inicia com a conservação da quantidade que se expressa na noção de número, é tardio na psicogênese, ocorrendo em média por volta dos 7/8 anos de idade. Ele nasce de uma diferenciação (acomodação) desse sistema lógico do qual é tributário - e nunca deixará de sê-lo. Como disse P14: “[...] o fundamento da matemática é a lógica”.

Nunes e Bryant (1997) chamam a atenção para a necessidade de a criança ter construídas as estruturas lógicas necessárias para construir a noção de número. Para entender a natureza 
ordinal do número, a criança precisa compreender que "se 3 é mais do que 2 e 2 é mais do que 1, então, devido a isso, 3 é necessariamente mais do que 1" (NUNES; BRYANT, 1997, p. 20); isso demanda a capacidade lógica da transitividade. "É ideia de Piaget de que a compreensão da transitividade é uma exigência para a compreensão verdadeira do número" (NUNES; BRYANT, 1997, p. 23). Para Piaget (1977b, p. 173), “[...] essa transitividade não cai do céu [...] ela é produzida pelas próprias ações, antes de se tornar um instrumento operatório generalizado".

Outra demanda lógica é compreender a conservação. "Entender conservação é saber que o número de um conjunto de objetos pode apenas ser mudado por adição ou subtração: todas as outras mudanças são irrelevantes" (NUNES; BRYANT, 1997, p. 21). Sem conservação, "as crianças não terão qualquer noção de número cardinal” (NUNES; BRYANT, 1997, p. 22); elas "estarão falando como papagaios as palavras que identificam os números" (NUNES; BRYANT, 1997, p. 22) Soma-se a essas qualidades lógicas, entre outras, "a atividade matemática mais básica de todas, que é a contagem” (NUNES; BRYANT, 1997, NUNES; BRYANT, 1997. p. 22). Entre essas outras, está a capacidade de saber "quais mudanças alterarão um número de elementos e quais não alterarão" (NUNES; BRYANT, 1997, p. 23) Sem isso, as crianças não compreenderão que $2+5=7$ e $7-2=5$; que $5+2-2=5$ e que $4+$ $3=3+4$; elas não entenderiam as regras básicas da adição.

\section{As crianças podem aprender como fazer adições e subtrações simples com grande facilidade, mas, de acordo com Piaget, elas não podem entender o que estão fazendo a menos que também captem as relações entre adição e subtração e a composição aditiva do número (NUNES; BRYANT, 1997, p. 23).}

Szeminska (1995, p. 9) investigou "Abstrações, diferenciações e integrações no emprego de operações aritméticas elementares”, em crianças de pouco menos de cinco anos de idade até pouco mais de treze. Ela mostra como o pensamento matemático surge da diferenciação quantitativa desse aparato lógico qualitativo; essa diferenciação é seguida de integração redundando em totalidades inexistentes anteriormente. Mostra também a complexidade desses processos no interior do processo maior de equilibração ou abstração reflexionante, que ocorre por sucessivos reflexionamentos e reflexões.

Pelo reflexionamento o sujeito retira, de um nível inferior, certas ligações que ocorrem, por exemplo, nas ações materiais, que são utilizadas sem consciência, e as transforma em objetos de pensamento. Segue-se então a reflexão, consistindo em reorganizações necessárias, no novo plano, em função da chegada desses objetos de pensamento, configurando a integração ou síntese. Tanto as abstrações reflexionantes, quanto as diferenciações e integrações, os reflexionamentos e as reflexões, são ações do sujeito. São elas que constroem a noção de 
número e que, interiorizadas, transformam-se em operações de soma e subtração, de multiplicação e divisão etc. Os resultados, diz Szeminska (1995) mostram os obstáculos que o sujeito precisa superar para construir essas totalidades só chegando a elas, com reversibilidade completa, por volta dos 11 a 12, e só consolidando as capacidades formais por volta dos 14 a 15 anos de idade.

Esses complexos e demorados processos são reduzidos, no empirismo, à cópia e à repetição do que as instâncias sociais ensinam, em especial a escola; no apriorismo, são reduzidos a elementos dados a priori, não raramente inatos. Em ambos, lembra Piaget (1978a), reduz-se o sujeito à passividade, a um repositório dos ensinos da sociedade, a um inerte social sem capacidade de se recriar e se reinventar; apenas de repetir, frequentemente sem compreender. Da concepção construtivista de desenvolvimento cognitivo e de aprendizagem, ao contrário, emerge um sujeito ativo que se transforma por força de suas ações, em interação com o entorno. Ações físicas, simbólicas, conceituais e, na continuidade, ações de tomadas de consciência pelas quais se apropria dos mecanismos das ações realizadas potencializando suas capacidades e, portanto, suas ações futuras; que transforma suas ações em operações; que coordena suas ações, retirando dessas coordenações a matéria prima de suas operações; que, na medida em que constrói o mundo da causalidade, constrói complementarmente o mundo inferencial, lógico-matemático; que, finalmente, constrói, abstraindo (PIAGET, 1995) de suas estruturas lógicas, suas capacidades matemáticas.

\section{Conclusões}

Uma epistemologia empirista define-se por conceber o conhecimento humano como resultante da pressão do meio, físico ou social, sobre os sentidos do corpo ou sobre a mente compreendida como primordialmente tábula rasa, determinando-a, e, posteriormente, como tábula rasa frente a cada novo conhecimento. Na fala dos docentes de Matemática entrevistados, ela aparece sob múltiplas formas: as noções matemáticas surgem da inculcação que os adultos vão fazendo nas crianças; a criança aprende tocando, apalpando; recém-nascidos nada sabem, não só de Matemática, incorporam tudo depois; tudo depende da estimulação que os adultos lhes proporcionam, se receberem muito estímulo irão se desenvolvendo na medida do que os pais vão transmitindo; essa determinação do sujeito pelo meio começa quando ainda no ventre materno, por exemplo, quando a mãe escuta música ou pelo que pai e mãe transmitem. Os verbos utilizados pelos entrevistados são: inculcar, ver, incorporar, tocar, apalpar, observar, estimular, transmitir, sendo que todos referem-se a sentidos do corpo, à estimulação, à 
percepção, não à ação do sujeito, de seu intelecto, de sua mente, de seu cérebro como imaginar, estimar, calcular, sonhar, abstrair, tomar consciência, investigar, operar, generalizar, refletir, criar, inventar. Diz Piaget (1979a, p. 53): "Nenhum conhecimento é devido apenas às percepções porque estas são sempre dirigidas e estruturadas por esquemas de ação”.

Reflexos desse empirismo aparecem nos mitos professados pelo ensino de Matemática (BECKER (2019) tais como: a Matemática está presente em tudo, está na natureza; as noções matemáticas vêm da natureza; a Matemática sempre existiu; a Matemática está na linguagem pois a linguagem já é Matemática - este parece ser corolário de outro mito mais geral de que a Matemática é apenas uma linguagem.

O que surpreende é a crença de que o meio determina o sujeito, o indivíduo, independentemente de seu desejo ou de sua vontade. Os docentes entendem que o feto e a criança pequena escutam e escutando aprendem muitas coisas que não entendem; eles retêm informações, mas não conseguem operar com elas; o aluno fica com a informação na sua cabeça, mas não a trabalha, esperando o dia em que, amadurecido, possa operar com ela. Para os maiores acontece o mesmo, pois eles aprendem conhecimentos que "ainda não podem assumir"; é como dar a eles muitos conhecimentos que armazenam, mas ainda "não podem analisar, não podem levar ao mundo real”. A criança pequena ouve música, mas não se comunica porque não sabe se expressar, mas seu cérebro está captando a informação; embora ela nada entenda, seu cérebro busca conectar (associar) o que ela escuta com o que ela já tem. Ela intui a noção de número e até a ideia ou conceito de número, pois, se falta um brinquedo, ela sabe. Está embutido nessas concepções um conceito de memória-depósito; depositam-se nessa memória conteúdos, que não precisam ser compreendidos, e que um dia poderão ser utilizados. A escola tradicionalmente trabalha com esse (pré)conceito, quase nunca tematizado e raramente criticado pelos docentes.

Na prática, os docentes entendem, com essa concepção epistemológica, que a condição para se passar de um conhecimento mais simples a um mais complexo é, apenas, por um lado aprendizagens prévias ou pré-requisitos em termos de conteúdo e, por outro, a maturação; e acrescentam que, para reter esse conhecimento é preciso repeti-lo: "primeiro trabalho eu acho que é a repetição"; "se eu der uma informação repetitiva, o cérebro acaba [...] encontrando uma lógica...”. Porém vimos que eles não consideram isso suficiente porque, na hora de procurar um suporte para sua concepção empirista, apelam (inconscientemente) para um apriorismo; o apelo que mais tem aparecido é a maturidade - determinação genética que faz aparecer capacidades aos poucos no decorrer do crescimento do corpo e independentemente do que o indivíduo faça -, seguida de seu corolário, a idade: tem que aguardar a idade certa. Ao 
fazer isso eles se contradizem, pois negam que a epistemologia empirista seja capaz de fundamentar suas próprias convicções. Mas não tomam consciência da contradição que vivem.

Quando o empirismo falha em fundamentar sua concepção epistemológica, o docente põe em cena apelos apriorísticos, tais como: as crianças "vêm com um certo legado dentro de seus neurônios", com "algo incorporado ao seu 'cerebrozinho"”, já trazem, ao nascer, algo de capacidade; os alunos não assumem um valor absoluto porque em seu "disco rígido" não há esse valor; é preciso encontrar coisas “... que estejam em seu 'disco rígido', para usá-las sempre"; para saber se podem aprender o que se quer ensinar, tem que observar "[...] se a maturidade que eles têm, nesse instante, permite entender esse conceito"; "o que a gente tem na cabeça [...] são círculos, linhas, pontinhos, coisinhas"; a criança “[...] não vai entender nada, mas seu cérebro está tentando encontrar a conexão [entre] o que ela está escutando com o que já tem"; quando sai do útero, o recém-nascido “... pensa que está em um espaço maior”. E até se atribui ao recém-nascido a capacidade de pensar.

Todos os docentes pensam a aquisição do conhecimento, com o qual trabalham, com uma abordagem empirista, mas esse empirismo é suportado implicitamente por um apriorismo, raramente explicitado. A função das entrevistas, mediante a análise proposta por esta pesquisa, é explicitar esse apriorismo que é responsável pela manutenção de mitos prejudiciais ao ensino de Matemática e à formação discente. Um desses mitos é o do talento: só compreenderá bem Matemática aquele que tiver nascido com talento (BECKER, 2012, p. 60); quem não nasce com talento, pouco poderá fazer em termos de aprendizagem de Matemática e pouco se poderá fazer por ele em termos de ensino de Matemática.

Intitulamos "simbiose" a interpretação dos casos em que empirismo e apriorismo mais ou menos se equilibram nas respostas dos entrevistados. Destacamos mais de uma dezena de passagens em que isso aparece. Afirmam os docentes aqui alinhados que todos nascem com certa habilidade matemática, uma matemática básica e universal que marca a estrutura do cérebro do recém-nascido. É a partir dessa herança genética que se constrói todo o resto; e o resto nos é dado pela cultura. A própria capacidade de aprender é inata, capacidade que o treinamento fortalece e melhora, como acontece com a música, o futebol. Há pessoas que nascem com mentes brilhantes, mas são poucas; a maioria precisa de boas estratégias para adquirir novos conhecimentos, pois a capacidade matemática pode ser uma mistura de talento e aprendizagem - se tem pouco talento precisará de mais aprendizagem, o que implica mais ensino e, portanto, mais repetição. A linguagem não aparece por ocasião do nascimento, pois o sistema nervoso não está suficientemente maduro, mas o hardware já está ali, tal como acontece com o computador; esse hardware é que permite criar um software, um programa, a linguagem. 
A gramática já está impressa no cérebro com a linguagem. Enfim, todos têm a ideia de número; essa ideia não depende da rodagem de um programa. Tanto a capacidade matemática quanto a de linguagem não aparecem logo porque falta maturidade suficiente, pois há níveis distintos de maturidade.

Como se vê, todos os docentes professam uma epistemologia empirista. Porém, ao serem desafiados a fundamentar essa concepção, apelam a um apriorismo pré-formista, inclusive inatista; às vezes, esse apriorismo é tão forte que se equipara ao empirismo - daí "simbiose". A dialetização de empirismo e apriorismo, superando a ambos na direção de um construtivismo, ou de uma dialetização das relações entre genoma e meio e entre aprendizagem e ensino, é rara, quase inexistente.

De construtivismo encontramos apenas fragmentos. Descartando uma docente que se diz construtivista, mas quase nada demonstra a respeito, sobra um docente que apresenta ideias construtivistas mais ou menos próximas do construtivismo piagetiano, tal como a de escalonamento de conteúdos em função das capacidades de abstração da criança - e não da lógica interna do currículo, como se procede tradicionalmente na escola. Para Nogueira (2017, p. 93), “A necessidade de se respeitar o nível cognitivo da criança, de se considerar o conhecimento prévio dela, bem como a importância de que o aluno seja sujeito de sua própria aprendizagem, são pressupostos piagetianos que implícita ou explicitamente orientam as investigações mais atuais na Educação Matemática."

Cotejando os resultados apresentados com resultados de pesquisa homônima realizada no Brasil (BECKER, 2012), podemos afirmar que eles acertam o passo no que diz respeito à predominância da concepção empirista, ao recurso ao apriorismo para justificar o empirismo e à quase ausência de concepção construtivista, de compreender que as capacidades cognitivas são construídas por abstração reflexionante ou experiência lógico-matemática; a diferença reside no fato de que a presença de concepções aprioristas é mais intensa nos entrevistados desta pesquisa a ponto de se equiparar às vezes à concepção empirista, e, num caso, de superála. A concepção construtivista, diferentemente das concepções empiristas e aprioristas, não é espontânea; tem que ser construída. Ela poderá ser construída apenas mediante crítica radical às epistemologias de senso comum, empiristas ou aprioristas, superando-as. É este o desafio da docência de Matemática, pois esta ciência é resultante de construções humanas, cujas construções implicam a dialetização do meio e da herança genética, e não da simples pressão do meio ou de dotações a priori ou inatas a (raros) organismos privilegiados.

Tanto a análise apresentada neste texto, quanto as conclusões a que ela nos levou, faz com que postulemos uma nova pedagogia e uma nova didática para o ensino de Matemática. E 
acrescente-se: muitas iniciativas, não referidas aqui, já tomaram a dianteira nessa direção, algumas há décadas.

Finalmente, observe-se que a concepção epistemológica construtivista não é espontânea como são espontâneas as concepções empiristas e aprioristas; é por isso que classifico estas como "epistemologias de senso comum" - todos os docentes, desta e de pesquisas anteriores, as manifestaram. A concepção construtivista nasce da dialetização dessas epistemologias conduzindo à superação de ambas, na direção de uma epistemologia da interação, da relação ou da construção cognitivas; portanto, de uma trabalhosa atividade crítica que precisa enfrentar e afrontar continuamente o senso comum que é sempre muito poderoso.

\section{Referências}

BECKER, Fernando. Construção do conhecimento matemático: natureza, transmissão e gênese.

Bolema - Boletim de Educação Matemática. Rio Claro, v. 33, n. 65, p. 963-987, dez. 2019.

Disponível em: $<$ http://www.scielo.br/bolema $>$. Acesso em 30 jun. 2020.

BECKER, Fernando. Educação e construção do conhecimento. $2^{\mathrm{a}}$ ed. Porto Alegre: Penso, 2012a.

BECKER, Fernando. A epistemologia do professor: o cotidiano da escola. $16^{\mathrm{a}}$ ed., $2^{\mathrm{a}}$ reimp. Petrópolis: Vozes, 2018.

BECKER, Fernando. A epistemologia do professor de matemática. Petrópolis: Vozes, 2012b.

BECKER, Fernando. Abstração pseudo-empírica e reflexionante: significado epistemológico e educacional. Schème, Revista Eletrônica de Psicologia e Epistemologia Genéticas. Marília: UNESP, v. 6, p. 103-127, 2014.

BECKER, Fernando. Abstração pseudo-empírica: significado epistemológico e impacto metodológico. Educação \& Realidade. Porto Alegre, v. 42, n. 1, jan./mar. 2017. p. 371-393.

CHOMSKY, N. A propos de structures cognitives e de leur développement: une réponse à Piaget. In: PIATELLI-PALMARINI, M. (Org.). Théories du langage, théories de l'apprentissage; le débat entre Jean Piaget et Noam Chomsky. Paris: Éditions du Seuil, 1979b. p. 65-87.

NOGUEIRA, C. M. I.; NOGUEIRA, V. I. O ensino de matemática no Brasil na perspectiva piagetiana: uma primeira aproximação ao estado da arte. Schème, Marília, v. 9, n. especial, p. 93-130, 2017.

NUNES, T.; BRYANT, P. Crianças fazendo matemática. Porto Alegre: Artes Médicas, 1997.

PIAGET, J.; SZEMINSKA, A. A gênese do número na criança. $2^{\mathrm{a}}$ ed. Rio de Janeiro: Zahar, 1975.

PIAGET, J. O nascimento da inteligência na criança. $3^{\mathrm{a}}$ ed. Rio de Janeiro: Zahar, 1978a.

PIAGET, J. A construção do real na criança. $3^{\mathrm{a}}$ ed. Rio de Janeiro: Zahar, 1979a.

PIAGET, J. A representação do espaço na criança. 1a ed. Porto Alegre: Artes Médicas, 1993.

PIAGET, J. Problemas de psicologia genética. $1^{\text {a }}$ ed. Rio de Janeiro: Forense, 1973. 
PIAGET, J. A tomada de consciência. $1^{a}$ ed. São Paulo: EDUSP/ Melhoramentos, 1977 b.

PIAGET, J. Fazer e compreender. $1^{\text {a }}$ ed. São Paulo: EDUSP/ Melhoramentos, $1978 \mathrm{c}$.

PIAGET, J. O desenvolvimento do pensamento; equilibração das estruturas cognitivas. $1^{\mathrm{a}}$ ed. Lisboa: Dom Quixote, 1977a.

PIAGET, J. Abstração reflexionante: relações lógico-aritméticas e ordem das relações espaciais. $1^{\mathrm{a}}$ ed. Porto Alegre: Artes Médicas, 1995.

PIAGET, J. Recherches sur la généralisation. $1^{a}$ ed. Paris: PUF, 1978b.

PIAGET, J. Development and learning. In: LAVATTELLY, C. S.; STENDLER, F. Reading in child behavior and development. New York: Hartcourt Brace Janovich, 1972. p. 7-19.

PIAGET, J. La psychogenèse des connaissances et sa signification épistémologique. In: PIATELLIPALMARINI, M. (Org.). Théories du langage, théories de l'apprentissage; le débat entre Jean Piaget et Noam Chomsky. Paris: Éditions du Seuil, 1979b. p. 53-87.

SZEMINSKA, A. Abstrações, diferenciações e integrações no emprego de operações aritméticas elementares. In: PIAGET, J. Abstração reflexionante: relações lógico-aritméticas e ordem das relações espaciais. $1^{a}$ ed. Porto Alegre: Artes Médicas, 1995. p. 9-29.

STEIN, E. Aspectos filosóficos e sócio-antropológicos do construtivismo pós-piagetiano - II. In: GROSSI, E. P.; BORDIN, J. (Orgs.). Construtivismo pós-piagetiano. Petrópolis: Vozes, 2009. p. 2635 .

Submetido em 09 de Julho de 2020. Aprovado em 25 de Janeiro de 2021. 